\title{
EFEITO DA INTENSIDADE DE LUZ SOBRE O AQUECIMENTO RESULTANTE DA IRRADIAÇÃO DE DIFERENTES APARELHOS FOTOPOLIMERIZADORES
}

Eloisa de Paula GODOY, Ana Paula Gebert de Oliveira FRANCO, Gislaine Cristine MARTINS, Alfonso Sanchez- AYALA, Stella Kossatz PEREIRA

O estudo avaliou o efeito da intensidade de luz no calor emitido por dois aparelhos fotopolimerizadores, um de lâmpada halógena Optilux (Demetron) com intensidade de luz de $550 \mathrm{~mW} / \mathrm{cm}^{2}$ e outro à base de LEDs BluePhase (Ivoclar/Vivadent) de $1100 \mathrm{~mW} / \mathrm{cm}^{2}$. Para o teste foi utilizado um termopar tipo-K conectado ao termômetro digital (Omegaette), um disco de dentina com $\quad 0,5 \mathrm{~mm}$ de espessura sobre o qual foi aplicado sistema adesivo SBMP (3M ESPE), fotoativado durante 20 segundos e realizado o registro de elevação de temperatura de cada aparelho fotopolimerizador. Sobre o sistema adesivo foi aplicado um incremento de $2 \mathrm{~mm}$ de resina composta Filtek Z350 (3M ESPE), fotoativada durante 40 segundos e registrada a elevação de temperatura. Através da ANOVA observou-se que durante a polimerização do sistema adesivo, o aparelho Optilux obteve valores de elevação de temperatura de $16^{\circ} \mathrm{C}$ e o aparelho BluePhase de $18^{\circ} \mathrm{C}$ $(p>0,05)$. Na fotoativação da resina composta foram registrados picos de elevação de temperatura de $5,8^{\circ} \mathrm{C}$ para o aparelho Optilux e $5,5^{\circ} \mathrm{C}$ para o aparelho BluePhase ( $p>0,05)$. O aparelho à base de LEDs gerou tanto calor quanto o de lâmpada halógena. $O$ incremento de resina composta diminui significativamente a temperatura emitida pelos aparelhos fotopolimerizadores. 